\title{
Design e Simbologia no Projeto de Mobiliário Litúrgico
}

\author{
Design and Symbology in the Liturgical Furniture Project
}

FORCATO, Marcelo dos Santos; Doutorando; Programa de Pós-Graduação em Design / Faculdade de Artes, Arquitetura e Comunicação / Universidade Estadual Paulista Júlio de Mesquita Filho

msforcato2@uem.br

DALBERTO, Anelise Guadagnin; Mestre; Universidade Estadual de Maringá

agdalberto2@uem.br

RAZZA, Bruno Montanari; Doutor; Universidade Estadual de Maringá

bmrazza@uem.br

LANDIM, Paula da Cruz; Doutora; Programa de Pós-Graduação em Design / Faculdade de Artes, Arquitetura e Comunicação / Universidade Estadual Paulista Júlio de Mesquita Filho

paula@faac.unesp.br

\section{Resumo}

Este artigo tem como objetivo alertar profissionais de design e arquitetura sobre a importância dos elementos simbólicos inerentes ao projeto de mobiliário litúrgico e da sua expressão como símbolo. Para isto, são apresentados conceitos das principais peças localizadas no presbitério altar, ambão e sédia -, bem como do presbitério do templo católico. Além disso, são expostas importantes referências quanto à simbologia em produtos de design sacros, assim como seus efeitos na assembleia. É apresentado um estudo de caso do desenvolvimento completo de uma capela católica, dando especial destaque ao desenvolvimento destes elementos. Além disso, foi realizada avaliação de diferencial semântico com o intuito de entender como os usuários percebem as características emanadas pelos respectivos mobiliários.

Palavras Chave: design de mobiliário litúrgico; simbologia e percepção pelo usuário.

\begin{abstract}
This article aims to alert design and architecture professionals about the importance of the symbolic elements inherent in liturgical furniture design and its expression as a symbol. For this, are presented concepts of the main pieces located in the presbytery - altar, ambo and sedia -, as well as of the presbytery of the catholic temple. In addition, important references are presented regarding symbology in sacred design products, as well as their effect on the assembly. A case study of the complete development of a Catholic chapel is presented, with a special emphasis on the development of these elements. In addition, a semantic differential evaluation was performed in order to understand how the users perceive the characteristics emanated by the respective furniture.
\end{abstract}

Keywords: design of liturgical furniture; symbology and user perception. 


\section{Introdução}

Quando se fala em liturgia católica, fala-se em sinais. Liturgia católica é o ritual onde se recorda e se celebra a vida, a morte e a ressurreição de Jesus Cristo (MILANI, 2006). Assim, a liturgia se expressa, se comunica por meio de sinais sensíveis dados por gestos, ações, elementos, paramentos, mobiliário, arquitetura e pela harmonia do conjunto do espaço sagrado. Borobio (2010) resume esta poética como a dimensão estética da liturgia. No entanto, além da estética a liturgia é dotada de simbolismo.

Segundo a visão antropológica de Eliade (1992), assim como a maioria dos templos religiosos, os espaços sagrados católicos também possuem características que os distinguem simbolicamente de tudo que se encontra ao seu redor. Neste contexto, a porta é um elemento simbólico que expressa fortemente a separação e a dualidade entre o profano (espaço externo) e o sagrado (espaço interno). Ao adentrar o espaço sagrado, suas formas, iluminação, cores, linhas, emoção, devem se unir em um movimento ascendente, que conduz ao céu (ELIADE, 1992; BOROBIO, 2010; NUCAP e PASTRO, 2012). Por esta premissa, todo espaço sagrado, da arquitetura ao mobiliário, pode por ser considerado símbolo.

Para a realização do ritual litúrgico, o mobiliário litúrgico possui primordial importância. Este é um produto de design que possui suas funções práticas, estéticas e simbólicas aptas a apoiar os ritos, contribuindo na construção do significado às ações executadas durante as celebrações. As três principais peças do espaço sagrado católico são o altar, o ambão e a sédia, os quais se localizam em uma área chamada presbitério.

Estes elementos são dotados de simbolismo e conceito que perduram por milênios, mas que devido às intervenções, em alguns casos acabam perdendo seu potencial de comunicação e informação. Aos poucos seus significados vão sendo esquecidos ou mal empregados. No Concílio Vaticano II, ocorrido no período de outubro de 1962 a dezembro de 1965, a Igreja propôs que a liturgia fosse mais direcionada aos fiéis de modo que se cumprisse seu verdadeiro valor dentro da celebração (SILVA, 2006). No entanto, a má aplicação destas mudanças provocaram distorção do sentido teológico e desvalorização pedagógica dos principais elementos litúrgicos (SILVA, 2006), o que se aplica, entre outros, ao projeto do próprio mobiliário. Borobio $(2010$, p.7) também menciona a respeito da descaracterização do espaço sagrado e seus elementos simbólicos acerca das mudanças pós Concílio:

Certamente, renovaram-se não poucos sinais e cenários: igrejas, presbitérios, batistérios, etc. Construíram-se novos templos e espaços. No entanto, pode-se também constatar que nem sempre se fez a reforma de maneira adequada. Que nem sempre se valorizaram os sinais. Que muitos espaços são impróprios e pouco adaptados. Que se insistiu mais no ilustrativo do que no significativo. Que não se deu suficiente valor ao 'capital simbólico' de que dispomos.

Além disso, Roque (2004) e Borobio (2010) se referem ao altar como um objeto com status elevado ao de obra de arte, já que sua função simbólica desde os primórdios da religião é fazer uma conexão entre o homem e o divino. Isto é justificado pela capacidade artística de sua criação, onde estão intrínsecos traços de estilo, cultura e técnica de uma época ou população, bem como pela função a ele destinada. Isto pode ser exemplificado pelo altar católico que, tanto litúrgica como simbolicamente, representa o próprio Jesus, que segundo a doutrina católica, é a única ligação do homem com Deus (ROQUE, 2004). 
O altar é o elemento católico que se expressa semanticamente de maneira mais forte e significativa. Porém, entende-se que esta importância deva ser estendida aos outros mobiliários litúrgicos, principalmente ao ambão e à sédia, peças imprescindíveis para a execução da ação litúrgica. Neste sentido, o design do conjunto poderia ser elevado ao mesmo status de obra de arte, complementando a semântica, função e beleza essenciais à liturgia.

Neste contexto, este artigo tem por objetivo tornar conhecidas as relações entre o design de produto e a comunicação estética e simbólica intrínsecas a estes elementos da igreja católica, de modo que em projetos futuros, de construção ou de reforma destes espaços, os profissionais de arquitetura ou design se utilizem das informações necessárias para o correto emprego da simbologia considerada no ritual litúrgico pelos mobiliários projetados. Além disso, este trabalho apresenta uma nova abordagem do design e da arquitetura, que se desdobra justamente na aplicação das características estéticas e simbólicas inerentes aos projetos de mobiliários litúrgicos católicos.

Para isto, o tópico seguinte apresenta breve estudo sobre o simbolismo na religião Católica Apostólica Romana e sua contribuição para a formação dos significados pelo homem religioso. Os tópicos subsequentes dissertam acerca dos principais mobiliários litúrgicos bem como sua relação com design e as interpretações propostas por suas simbologias. É apresentado ainda, o método de conceituação, desenvolvimento e avaliação da arquitetura e design de um espaço sagrado e da poética semântica que se construiu neste projeto. As considerações finais evidenciam proposições e possibilidades de trabalhos futuros.

\section{O Simbolismo no Mobiliário Litúrgico Católico}

A capacidade do ser humano em interpretar e dar significado aos objetos está intrínseca à sua percepção desde as primeiras civilizações. Da mesma forma, o simbolismo esteve e está presente em todas as religiões (ELIADE, 1992).

O simbolismo é expresso por meio de símbolos. Um símbolo, de acordo com Ferreira (2004), é a representação não material de um objeto material. No entanto, o símbolo pode ser interpretado diferentemente de acordo com o repertório de cada pessoa, podendo representar uma ou outra coisa. Neste sentido, tudo pode se tornar símbolo, mas, ao mesmo tempo adquirir diferentes significados (RIBEIRO, 2010).

Assim também, na linguagem do design, os signos permeiam as interpretações e os significados. Repletos de signos estão também os desenhos arquitetônicos dos templos sagrados católicos, os quais possuem linhas e movimentos formais que conduzem ao céu (Figura 1), como abóbodas, pé direito alto, iluminação zenital, colunas delgadas, entre outros. Esta configuração procura transmitir ao observador uma mensagem de condução e de proximidade com Deus, o que pode sinalizar ainda sensação de amplitude e, da grandiosidade do amor de Deus. Embora estes sinais sensíveis, como preconiza Silva (2006), sejam oriundos de um bom projeto arquitetônico, vários elementos que compõem o espaço sagrado, principalmente seu interior, são produtos de design, como por exemplo, o mobiliário. 
Figura 1: Interior da Igreja Matriz São Sebastião - Japurá-PR

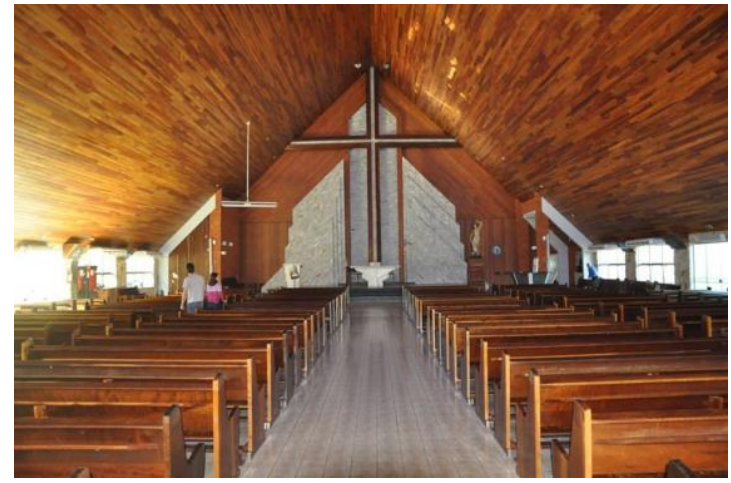

Foto: Autoria própria, 2016.

O presbitério do templo católico (Figura 2) é o local do espaço sagrado de onde o padre, diácono ou ministro realizam as ações litúrgicas (SECRETARIADO..., 2003, n.294). Geralmente encontra-se destacado em relação aos demais espaços do templo na intenção de dar visibilidade aos elementos que ali se encontram (SECRETARIADO..., 2003, n.295; NUCAP e PASTRO, 2012). Pastro $(1999$, p.65) defendia que o presbitério fosse concebido antes mesmo de qualquer elemento arquitetônico do templo, pois é "o lugar mais importante de todo o espaço celebrativo" sendo o ponto de partida para o projeto e forte elemento conceitual no templo. É no presbitério que se encontram os elementos fundamentais do espaço litúrgico: o altar, o ambão e a sédia (PASTRO, 1999; MILANI, 2006; SILVA, 2006).

Figura 2: Presbitério (Igreja Matriz São Sebastião - Japurá-PR).

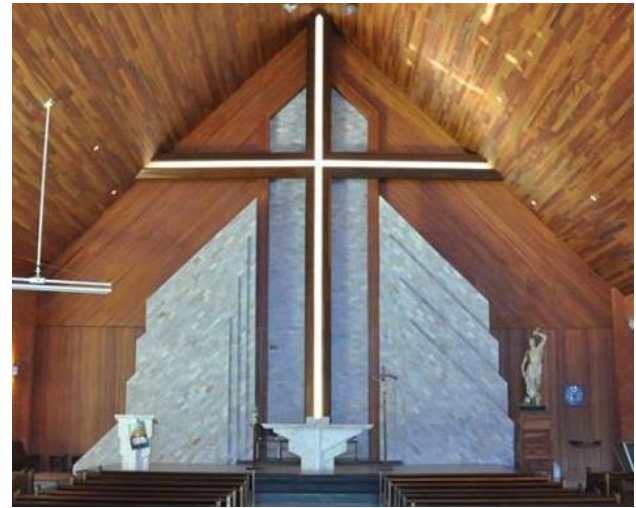

Foto: Autoria própria, 2016.

O altar (Figura 3) é o elemento central do templo. É nele que se concentra a fé católica (PASTRO, 1999; SECRETARIADO..., 2003, n.296; MILANI, 2006; SILVA, 2006; BOROBIO, 2010; NUCAP e PASTRO, 2012). Este mobiliário assemelha-se muito com uma mesa, porém, apresenta simbologia significativa, conforme relata Borobio (2010, p.66):

O altar cristão quer expressar a íntima relação desses dois aspectos: o do sacrifícioimolação e o do convite ou ceia do Senhor. O sinal mais visível, a mesa com o pão e o vinho, remetem mais diretamente ao aspecto convivial ou de banquete da Eucaristia; ao passo que a mesa com a ara, junto com o pão partido e o sangue derramado, remetem mais diretamente ao sacrifício de Cristo na cruz, presente na Eucaristia. 
A Instrução Geral ao Missal Romano - IGMR preconiza que o altar seja preferencialmente fixo ao presbitério, afastado da parede permitindo andar em seu entorno e celebrar de frente para a assembleia, constituído de material sólido, rígido, nobre e digno, preferencialmente de pedra. Admite-se também a utilização de outro material, tradicional ou de costume de cada região, desde que mantenha as características citadas anteriormente. É importante que haja moderação na ornamentação do altar, sendo recomendado utilizar apenas o necessário para a ação litúrgica. Um crucifixo pode ser mantido sobre o altar de forma contínua para lembrar aos fiéis seu significado (SECRETARIADO..., 2003).

O ambão (Figura 4), no espaço litúrgico, é o mobiliário de onde se proferem as leituras bíblicas, salmos, a homilia e as proposições de intenção universal (SECRETARIADO..., 2003). A palavra ambão vem "do grego 'anabaino' que significa subir, porque costuma estar em posição elevada" (SILVA, 2006, p.11). Para a religião católica simboliza o lugar de onde Deus fala. Também é chamado de mesa da palavra. De fato, é sempre colocado em local elevado (no presbitério) para que possibilite a atenção de todos os fiéis.

Figura 4: Ambão (Matriz São Sebastião - Japurá-PR).

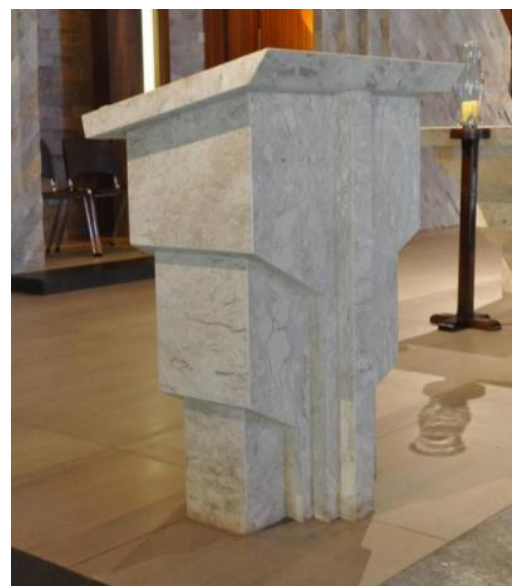

Foto: Autoria própria, 2016.

Borobio (2010) relata que o ambão é repleto de significados. Na simbologia católica, Deus se manifesta revelando, por meio do que é proferido, caminhos para a salvação. Sendo assim, deve ser compreendido como um instrumento para a anunciação da salvação dos homens onde a atenção deve estar voltada durante a liturgia da palavra. Por isso, a necessidade de local de destaque, seja no presbitério ou próximo à assembleia (MILANI, 2006). A IGMR indica que o ambão, assim como o altar, seja constituído de material sólido e digno, recomendando também que exista unidade entre os elementos pertencentes ao presbitério (SECRETARIADO..., 2003).

A palavra sédia/cátedra (Figura 5) vem do grego "kathédra", "sedes" (BOROBIO, 2010), também chamada de cadeira da presidência (SILVA, 2006). É neste mobiliário que fica sediado o presidente da celebração, seja ele o bispo, o padre ou o diácono da comunidade. Em catedrais é reservada apenas ao bispo e é chamada de cátedra. Nas outras igrejas pode também ser utilizada pelo bispo em celebrações especiais, mas é geralmente utilizada pelos padres e diáconos sendo chamada simplesmente de sédia ou sede. Possui riqueza simbólica e representa o local destinado ao próprio Cristo: 
O simbolismo da cátedra ou sede deve representar Cristo Mestre, que prega e ensina a seus apóstolos, sentados ao seu redor. Compreende-se que seja símbolo da presença do Mestre, de sua autoridade magisterial, de veneração e reconhecimento de seu ensinamento. Por isso, normalmente, os bispos, sucessores dos apóstolos, pregavam da sede. [...] Essa função adquire maior significado quando se trata da cátedra, onde o bispo tem sua "sede" [...]. A catedral é, portanto, a mais importante de todas as igrejas e "o centro da vida litúrgica da diocese" (BOROBIO, 2010, p.69-70).

Figura 5: Sédia (Matriz São Sebastião - Japurá-PR).

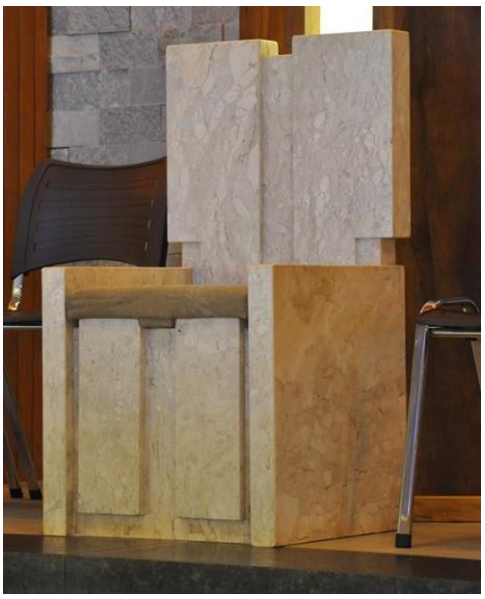

Foto: Autoria própria, 2016.

Borobio (2010) complementa que aquele que ocupa a presidência da celebração, simbolicamente, assume o lugar de Cristo e personifica-o. A IGMR recomenda a localização da sédia no fundo do presbitério, atrás do altar em um nível mais elevado, facilitando a visibilidade da assembleia (SECRETARIADO..., 2003). Pode estar também na lateral do presbitério, caso a arquitetura e disposição dos elementos assim exija. Não deve possuir aparência que lembre um trono, pois segundo Silva (2006, p.40), "a presidência é antes de tudo um serviço".

Diante do que está exposto, fica evidente que há uma importante carga simbólica no que concerne ao conjunto do principal mobiliário litúrgico que compõe o presbitério. É importante pensar que é responsabilidade do designer o projeto das características simbólicas inerentes a estes elementos no momento da sua concepção, o que sugere trabalho conjunto do design e da arquitetura para a ideação do espaço sagrado.

Mesmo que o Concílio Vaticano II (1962-1965) tenha estimulado certa restauração na liturgia católica, bem como instituído uma série de mudanças no sentido de tornar o espaço sagrado mais próximo dos fiéis e apropriado à oração, infelizmente, como afirma Borobio (2010), nem sempre as reformas e construções destes templos são realizadas de maneira adequada. Em muitos casos o que se percebe é a desvalorização dos sinais, insistência "mais no ilustrativo do que no significativo", descaracterizando o valor simbólico inerente ao espaço sagrado (BOROBIO, 2010 , p.7). Consequentemente, em função de projetos inadequados, seja de construção ou de reforma, o que acaba ocorrendo contemporaneamente é a presença de ruído na unidade da comunicação proporcionada pela simbologia dos elementos que compõem o templo sagrado. 0 tópico seguinte explora as relações entre simbolismo, design e o mobiliário litúrgico.

\subsection{Simbolismo nos Produtos de Design Sacros}


O homem religioso quando vai ao local de oração se depara com diferentes categorias de objetos. Löbach (2001) classifica os objetos industriais em quatro categorias: objetos naturais, objetos modificados da natureza, objetos de arte e objetos de uso. Nos templos católicos, por exemplo, é possível o contato do homem com objetos destas quatro categorias, o que sugere a riqueza de significados presente nestes ambientes. No entanto, é importante ressaltar que, mesmo estes elementos (altar, ambão e sédia) possuindo funções específicas, as quais são próprias das ações litúrgicas, o que os classifica também como objetos de uso, seus objetivos vão muito além do cumprimento das funções práticas.

Para aqueles que frequentam o templo, o mobiliário litúrgico possui funções estéticas que estão mais ligadas às questões sensoriais, à recepção de uma mensagem e à linguagem do objeto. Löbach (2001) e Sudjic (2010) relatam que a cor, forma, texturas, materiais e superfícies são elementos estéticos que possuem representatividade e significado. Estas características Ihes confere uma segunda classificação: a de objeto artístico. Estes, por sua vez, procuram satisfazer as necessidades psíquicas e espirituais do observador/receptor. Bonsiepe (2011) também menciona que esta dimensão estética dos produtos se comunica através da subjetividade. Para Baudrillard (1998) esta "estratégia da aparência" é considerada um dos atributos básicos do design.

Neste sentido, o simbolismo presente no mobiliário litúrgico é percebido pela sua configuração formal, por isso, está intimamente ligado à questão estética. Além disso, a função simbólica dos produtos (no caso, mobiliário), age diretamente na espiritualidade do homem, estimulando também experiências e sensações psíquicas e sociais. Juntamente com a função simbólica, a função estética tem a finalidade de atrair o olhar e, consequentemente a atenção do observador (LÖBACH, 2001) para o mobiliário.

Acredita-se que a beleza destes elementos seja o ponto central de atenção dos fiéis, já que para Borobio (2010) a beleza é fator construtivo da ação litúrgica. Assim, é indispensável que haja unidade em todas as esferas do ambiente sacro. Os três elementos principais para a realização da ação litúrgica devem possuir unidade formal, estética e conceitual no intuito de tornar o espaço litúrgico mais belo e harmonioso. Além disso, é importante que o projeto seja pensado unindo características que remetam ao natural, utilizando-se de pedras, vegetais, materiais naturais; e linhas que remetam à harmonia e ordem. Borobio (2010) acrescenta que é na união destas duas características que se obtém a beleza na liturgia, bem como no espaço sagrado.

No tópico a seguir, será apresentado um estudo de caso em que estes preceitos foram aplicados no desenvolvimento do templo e mobiliário litúrgico de uma capela católica. É necessário ressaltar que no estudo de caso apresentado está presente uma importante peça que é o batistério ${ }^{1}$, o qual teve importância simbólica na construção do conceito do projeto. Este não foi mencionado no desenvolvimento teórico deste artigo porque a IGMR sugere que este elemento esteja em local de destaque no templo, porém, não no mesmo nível daqueles tratados aqui anteriormente (SECRETARIADO..., 2003).

\section{Materiais e Métodos}

Este trabalho apresenta-se ora como uma pesquisa aplicada, pois seus resultados foram implementados em um caso real, ora como pesquisa exploratória, já que estes mesmos resultados

\footnotetext{
${ }^{1}$ Bastistério ou pia bastimal é o mobiliário onde se realiza o batismo. "Pode ser uma pequena pia batismal que permita o batismo somente por aspersão, ou uma fonte batismal que permita o batismo por imersão" (MILANI, 2006: 43).
} 
são pouco explorados em pesquisas da área do Design, sendo difícil formular hipóteses precisas (GIL, 1999). Para sua realização foram realizadas 5 fases, a saber: 1) desenvolvimento de projeto arquitetônico; 2) projeto de interiores e mobiliários litúrgicos; 3) revisão bibliográfica; e 4) implantação e 5) análise dos mobiliários litúrgicos pós-implantação.

As fases 1 e 2 estavam contidas em um Projeto de Extensão universitária que envolveu 2 docentes e 3 discentes do curso de Design da UEM. Utilizaram-se processos de desenvolvimento comuns à arquitetura e design. No processo de design, utilizou-se a ferramenta brainstorming para ideação do conceito, bem como informações oriundas do projeto arquitetônico com o objetivo de manter similaridade com o conceito arquitetônico. Os recursos para execução da Capela e do mobiliário foram oriundos da comunidade local e da própria Igreja.

A fase 3 surgiu da carência de bibliografias específicas que fornecessem parâmetros para o desenvolvimento de mobiliário voltado para espaços litúrgicos. Para sua realização foi criadoum Projeto de Pesquisa institucional que propunha estudar e reunir parâmetros com o objetivo de informar e contribuir com profissionais no projeto de novos templos e mobiliários litúrgicos. Consistiu de pesquisa bibliográfica apoiada em livros e artigos nacionais e internacionais.

Por fim, a fase 4 consistiu da implantação, inauguração e dedicação da Capela e seu mobiliário e análise do mobiliário pós-implantação avaliando seus aspectos ergonômicos (suprimido neste artigo) e a percepção dos aspectos simbólicos pelos fiéis/usuários. A avaliação dos aspectos simbólicos foi realizada por meio de entrevistas estruturadas com os usuários diretos do mobiliário (no caso, somente altar, ambão e sédia), bem como membros do conselho da capela (participantes ativos durante o projeto) e público em geral.

O principal objetivo desta avaliação foi identificar como estes usuários percebem este mobiliário e quais as principais associações simbólicas que realizam. Para a realização desta avaliação foi empregado o método do Diferencial Semântico proposto por Osgood et. al. (1957). O método consiste em listar uma série de escalas de adjetivos bipolares (palavras antônimas) que definam o objeto ou elemento de análise, de forma clara, de fácil interpretação e sem ambiguidades (PASQUALI, 2010), como no exemplo abaixo.

$$
\text { BOM_1_:_2_:_3_:_4_:_5_:_6_:_7_MAU }
$$

Cada espaço recebe um valor numérico compreendendo, por exemplo, de 1 a 7, que definirá a direção e a distância do polo, a direção indica a qualidade e a distância a intensidade quanto mais próximo de um polo maior a percepção daquele adjetivo está presente, e quanto mais ao centro maior a ausência da percepção (LOPES et. al., 2011; ALMEIDA et. al., 2014). Para a construção das escalas foram realizadas busca de adjetivos na literatura litúrgica, seleção de adjetivos e antônimos (total de 26 termos) e avaliação pelos usuários-alvo. Os resultados e discussões são apresentadas à seguir.

\section{Resultados e Discussão}

\subsection{Design de mobiliário litúrgico e simbolismo: um estudo de caso}

Para ilustrar a experiência projetual de design de mobiliário litúrgico, será discriminado aqui o processo de desenvolvimento do altar, ambão, sédia e batistério da Capela São Vicente de Paulo do município de Assaí-PR. Este desenvolvimento esteve integrado a um Projeto de Extensão Universitária que teve por objetivo desenvolver o projeto arquitetônico e do mobiliário daquela 
capela. O mesmo contou com a participação de docentes e discentes do curso de Design da Universidade Estadual de Maringá, membros da comunidade externa, além de engenheiro civil e representantes do conselho paroquial local.

A Capela São Vicente de Paulo está localizada no Conjunto COPASA em Assaí-PR. A mesma atende uma população aproximada de 3000 mil pessoas. A antiga capela já estava pequena para a acomodação da assembleia, por isso, a paróquia decidiu por construir uma estrutura mais ampla. Neste artigo o processo de desenvolvimento da arquitetura do templo está suprimido já que se objetiva demonstrar os trabalhos de planejamento, design e simbolismo presente do mobiliário. No entanto, é válido discorrer sobre o conceito arquitetônico do edifício que se baseou na ideia formal do antigo templo que ali existia o qual também apresenta ressonâncias no mobiliário litúrgico.

A tipologia de telhado de duas águas, que remete a ideia formal de 'casa' foi mantida na nova proposta a fim de criar a ligação entre o antigo e o novo templo, além de reafirmar a condição do edifício como 'casa do povo de Deus' (Figura 6). A nova construção abraça a cruz, trazendo-a para dentro de sua estrutura e lembrando que a salvação vem da cruz, uma cruz robusta, que permite enxergar além de si, por meio de seu vazado. Ao lado da cruz está o campanário para simbolizar a alegria da salvação e da reunião do povo de Deus. A organização interna proporciona a reunião em torno do altar. Por isso não existe frente e fundos, mas a proximidade de todos em torno da mesa do sacrifício, de onde vem a luz do 'alto' simbolizada pela abertura zenital sobre o altar.

Figura 6: Capela antiga (à esquerda) e capela nova (à direita).

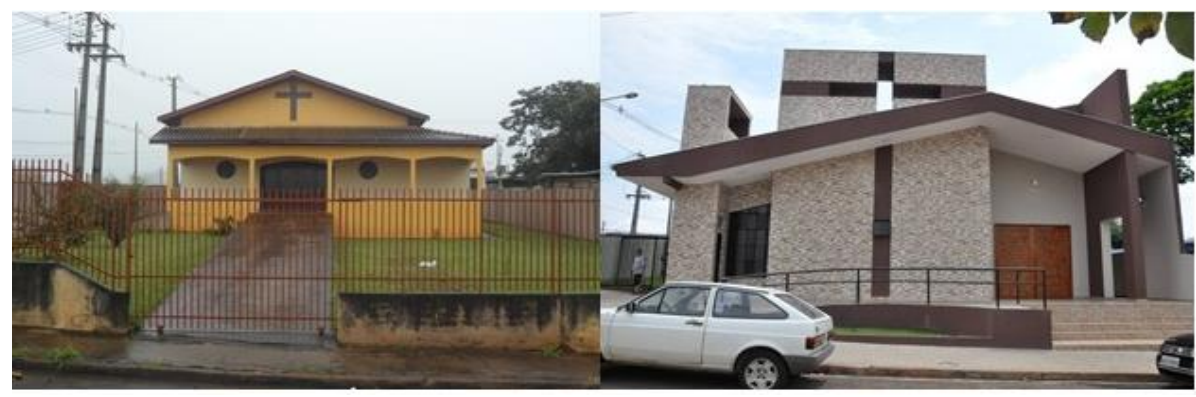

Foto: Elaborado pelos autores, 2018.

\subsection{Conceituação}

O processo de criação do mobiliário litúrgico apoiou-se na história do padroeiro da referida capela: São Vicente de Paulo. Em termos gerais, a vida de Vicente de Paulo se resume a muita simplicidade e origens humildes. Nasceu em 1581 na cidade de Pouy no Sul da França. Sua família toda, muito religiosa e composta por 8 pessoas, trabalhava muito para se sustentar. Desde criança, Vicente sentia compaixão pelos pobres, chegando a distribuir alimento que era da família para mendigos. Aos 19 anos, ordenou-se sacerdote e dedicou grande parte de seu sacramento ao serviço aos pobres, doentes, feridos e mais necessitados. Defendia o direito de igualdade a todos. Seu trabalho se concentrava em ações de caridade, humildade, amor ao próximo e abraço aos pobres. Morreu em 1660, aos 79 anos, mas deixou um legado de congregações e movimentos que até hoje seguem seu modelo de vida e dedicação aos mais necessitados (ARAUTOS..., 2011). 
As principais características da história de São Vicente de Paulo e imagem que traduz a sua vida (Figura 7) foram utilizadas para a conceituação e abstração de elementos para o projeto dos mobiliários litúrgicos da capela.

Figura 7: Painel conceitual.

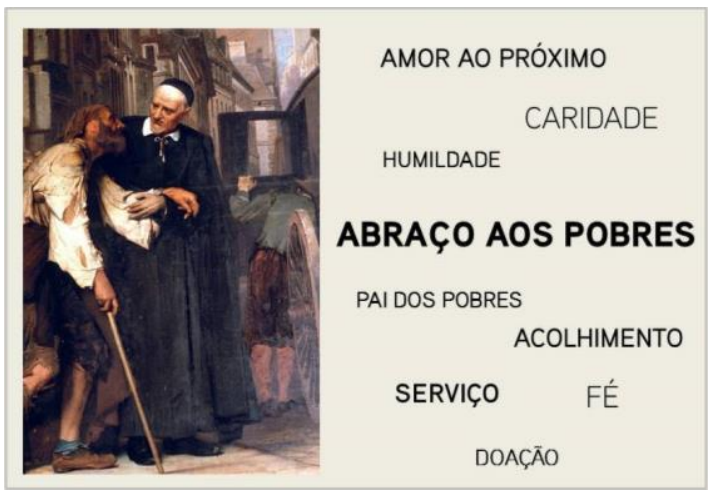

Fonte: Elaborado pelos autores, 2015.

Várias alternativas foram desenvolvidas pela equipe de participantes do projeto, as quais estão suprimidas neste artigo com a intenção de atender às normas de publicação deste congresso. No entanto, o conceito que obteve melhores resultados estava apoiado ao termo "abraço aos pobres".

\subsection{Desenvolvimento}

As gerações de alternativas para o altar, o ambão, a sédia e o batistério basearam-se em elementos formais que simbolizassem acolhimento e abraço. Para isto, foram utilizadas inserções de volumes com materiais em cores diferentes que causassem a sensação de envolvimento no observador.

O projeto utilizou formas que representassem o conceito de envolvimento. Estes elementos, sejam eles volumes maiores ou menores, ocuparam duas ou três faces dos mobiliários, sugerindo uma ação de abraçar. Importante mencionar aqui a relevância da aplicação da simbologia já nas primeiras fases de desenvolvimento de mobiliários litúrgicos, pois esta atividade conduz o designer por uma criação mais apoiada em significados. Além disso, é a simbologia, intrínseca aos elementos, que comunica o conceito do projeto, contribuindo para a absorção das informações que as peças devem passar para a assembleia. Como já mencionado, o templo católico é carregado de simbologia e seus elementos somente terão consonância se forem projetados já com esses significados e conceitos.

As etapas de desenvolvimento projetual de arquitetura englobaram reuniões com o Conselho Paroquial, o qual era composto pelo pároco e membros da comunidade. Estas reuniões tinhama finalidade de discussão do projeto arquitetônico. Posteriormente, houve reunião com a comunidade para apresentação do projeto. Em um segundo momento ocorreu uma reunião com o mesmo Conselho para apresentação dos conceitos adotados no projeto do mobiliário. Nesta etapa quatro propostas foram apresentadas para os presentes e, das quatro opções, foram selecionadas duas por meio de votação e, destas duas, uma foi a escolhida para execução, o que também aconteceu por meio de votação. Na figura 8 estão ilustrados o altar e a sédia escolhidos 
pelo Conselho. Foi sugerido pelos designers a confecção do altar em pedra, em tons escuro e claro, o qual foi idealizado em dois módulos. O módulo central, de cor clara, possui altura um pouco maior em relação ao módulo externo de cor escura.

Este jogo de alturas na volumetria do mobiliário tentou expressar que mesmo os mais necessitados sendo a maioria (representados pelo módulo claro) em relação a São Vicente de Paulo (representado pelo módulo escuro), este os abraçava por meio de sua bondade e caridade, simbolizando este acolhimento. Ao mesmo tempo, a cor escura representa a batina de São Vicente e a cor clara simboliza Cristo representado no pobre.

Figura 8: Ilustração do altar e sédia (projeto para Capela São Vicente de Paulo - Assaí - PR).
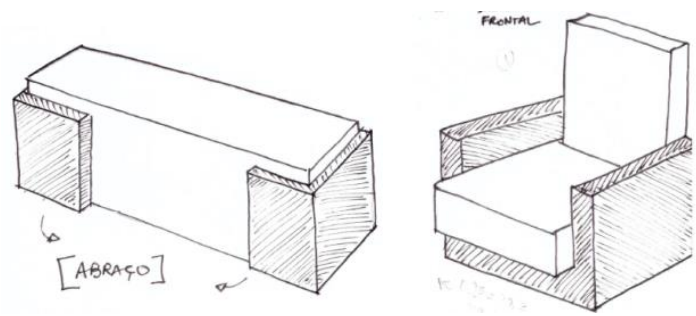

Foto: Elaborado pelos autores, 2015.

A sédia manteve essa idealização sugerindo a diferenciação entre os envolvidos. Ao assento e encosto foi sugerida a pedra clara e na parte inferior e laterais, as quais formam o apoio para os braços, foi sugerida a pedra escura. Esta composição tentou representar novamente o serviço que São Vicente de Paulo oferecia aos mais necessitados. Neste sentido, a pedra escura apoia a pedra clara, simbolizando acolhimento, colo.

$\mathrm{Na}$ figura 9 estão ilustrados o ambão e o batistério. Como estes mobiliários estão geralmente dispostos lateralmente em relação ao altar e sédia, foram idealizados em conjunto. Por uma questão de unidade conceitual foi mantida a utilização das pedras claras e escuras.

Figura 9: Ilustração do ambão e batistério (projeto para Capela São Vicente de Paulo - Assaí - PR).
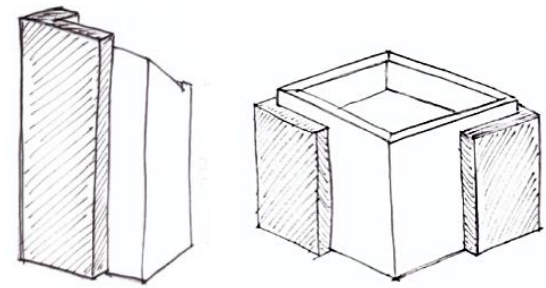

Foto: Elaborado pelos autores, 2015.

O ambão possui o volume posterior em pedra clara, havendo um volume em pedra escura cobrindo parte de sua lateral esquerda e frente. De forma conjunta, o batistério possui seu volume central (bacia) em pedra clara e volumes laterais em pedra escura. Estando as peças posicionadas a frente do presbitério, o ambão na lateral esquerda e o batistério na lateral direita, ambos são "abraçados" pelos volumes escuros, o que simboliza o abraço de São Vicente de Paulo aos mais necessitados e o abraço de Deus em todo o presbitério. 
Foi realizada a simulação dos mobiliários e espaço sagrado em software de modelagem virtual tridimensional. A figura 10 simula como ficaria o presbitério após a execução dos referidos mobiliários litúrgicos.

Figura 10: Modelagem virtual do presbitério (Capela São Vicente de Paulo - Assaí - PR).

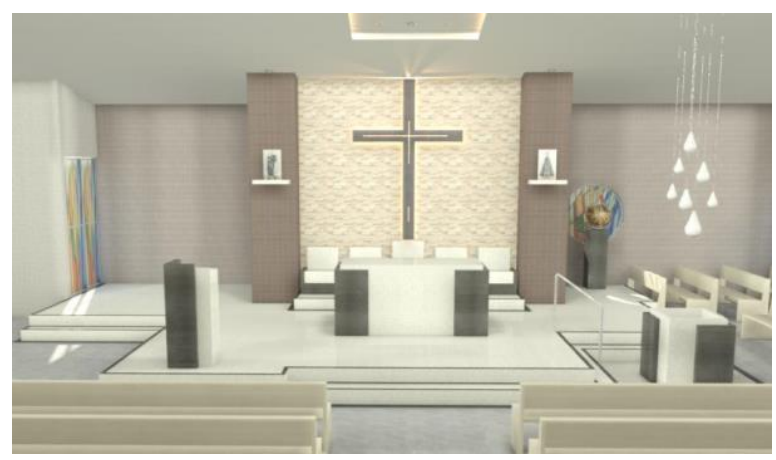

Foto: Elaborado pelos autores, 2015.

$\mathrm{Na}$ imagem, é possível observar que as características simbólicas projetadas para estes mobiliários tiveram a intenção de cumprir com seu papel de comunicação, chamando a atenção da assembleia para os mesmos. Também a sugestão dos materiais contempla o que regulamenta a Instrução Geral ao Missal Romano. As quatro peças do mobiliário litúrgico foram produzidas em granito verde labrador (cor escura) e branco dallas. A utilização da pedra, como já mencionada, é recomendada pela Igreja e dá aos mobiliários rigidez, nobreza, longevidade e por isso, dignidade. Porém, suas formas geométricas the conferem simplicidade. Estas características estão plenamente alinhadas à história do padroeiro da capela e às simbologias inerentes ao espaço sagrado, que deve passar à assembleia a sensação da presença de Cristo. Na figura 11 pode-se observar a fotografia da Capela após a execução dos mobiliários no local.

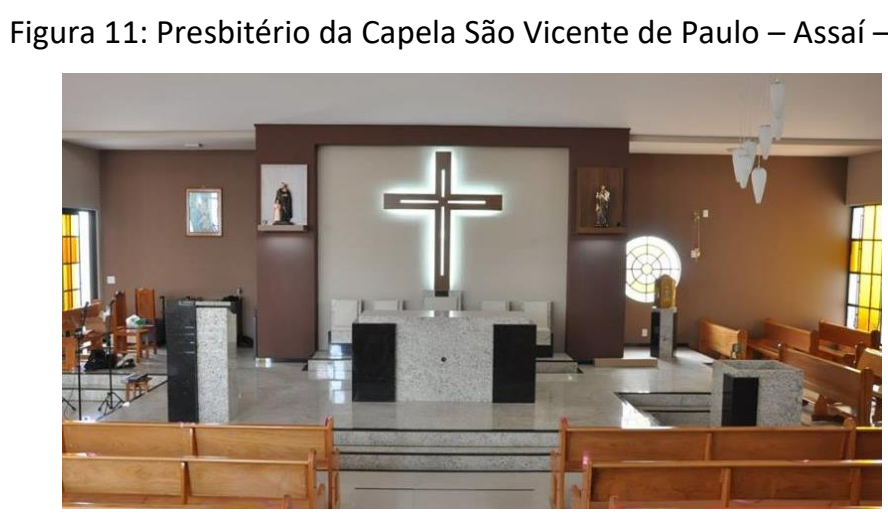

Foto: Dalberto, 2015.

Percebe-se na imagem que os volumes do batistério foram montados na posição contrária, descaracterizando a representatividade do "abraço" ao presbitério. No entanto, outros elementos do espaço litúrgico do presbitério reforçam as questões simbólicas inerentes ao espaço litúrgico. A cruz principal do presbitério, feita em madeira com iluminação embutida, recorda o madeiro da crucificação e possui um rasgo por onde "passa a luz" que simboliza a vida que transcende a 
morte, como o volume inserido na fachada do edifício. A linha vertical também conduz o olhar ao céu. A forma da parede do fundo do presbitério sugere duas linhas verticais que também conduzem ao alto. Neste sentido, o conjunto dos elementos que compõe o presbitério, mobiliário litúrgico, cruz, volumes e acabamentos se somam na construção para uma simbologia adequada neste espaço sagrado.

No dia 27 de setembro de 2015, durante o rito de dedicação da capela, o conceito do conjunto foi lido à assembleia, sendo aparentemente bem aceito pela comunidade.

\subsection{Diferencial Semântico}

Para a avaliação do diferencial semântico foram entrevistadas 16 pessoas da comunidade de Assaí, da Capela São Vicente de Paula. Dentre elas dois padres que lá atuavam, e membros da comunidade, algumas pessoas presentes na comunidade há menos de 4 anos, mas a maioria pertencentes a mesma há quase 20 anos. Os entrevistados responderam também a uma breve entrevista sobre suas opiniões sobre as capelas nova e antiga, no intuito de descobrir quanta ligação estas haviam criado com a capela antiga e se isto poderia influenciar na sua avaliação da nova.

Para cada peça do mobiliário (altar, ambão e sédia) foi aplicado o mesmo protocolo de avaliação com as escalas de adjetivos bipolares. Isto permitiu compreender a unidade entre as três peças de mobiliário litúrgico avaliado. Os adjetivos e sinônimos utilizados foram: nobre - comum; natural - artificial; durável - efêmero; sóbrio - extravagante; bonito - feio; sólido - frágil; monumental - trivial; atemporal - transitório; divino - terreno; equilibrado - desproporcional; modesto - luxuoso; acolhedor - desagradável; limpo - poluído.

A partir desta tabela foram gerados os resultados finais que foram utilizados, efetivamente, para a avaliação do mobiliário, pois eles dão uma "nota" para cada item demonstrando qual de cada par de itens tem mais representatividade para cada uma das peças. Para o resultado final, primeiramente, cada coluna foi multiplicada por sua respectiva pontuação

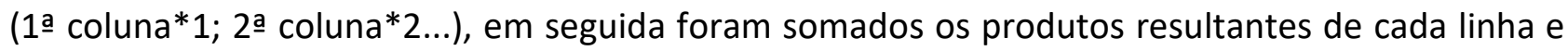
dividido por 7 (que é o total de colunas), obtendo-se dessa forma uma pontuação para cada item (Quadro 1). As palavras na tabela que estão em negrito são aquelas em que pontuação se mostra mais aparente no projeto.

Quadro 1 - Resultado do Diferencial Semântico para altar, ambão e sédia (respectivamente).

\begin{tabular}{rrl}
\hline & Altar & \\
\hline Nobre & 3,1 & Comum \\
Natural & 2,6 & Artificial \\
Durável & 4,1 & Efêmero \\
Sóbrio & 3,1 & Extravagante \\
Bonito & 4,1 & Feio \\
Sólido & 4,3 & Frágil \\
Monumental & 2,3 & Trivial \\
Atemporal & 2,4 & Transitório \\
Divino & 1,9 & Terreno \\
Equilibrado & 3,7 & Desproporcional \\
Modesto & 1,4 & Luxuoso \\
Acolhedor & 4,0 & Desagradável \\
Limpo & 4,3 & Poluído \\
\hline
\end{tabular}

\begin{tabular}{rrl}
\hline \multicolumn{3}{c}{ Ambão } \\
\hline Nobre & 3,7 & Comum \\
Natural & 2,7 & Artificial \\
Durável & 4,3 & Efêmero \\
Sóbrio & 3,9 & Extravagante \\
Bonito & 4,0 & Feio \\
Sólido & 4,3 & Frágil \\
Monumental & 2,4 & Trivial \\
Atemporal & 3,3 & Transitório \\
Divino & 2,7 & Terreno \\
Equilibrado & 3,9 & Desproporcional \\
Modesto & 2,4 & Luxuoso \\
Acolhedor & 4,3 & Desagradável \\
Limpo & 4,3 & Poluído
\end{tabular}

\begin{tabular}{rll}
\hline & \multicolumn{2}{c}{ Sédia } \\
\hline Nobre & 1,6 & Comum \\
Natural & 2,4 & Artificial \\
Durável & 3,9 & Efêmero \\
Sóbrio & 2,9 & Extravagante \\
Bonito & 2,9 & Feio \\
Sólido & 3,7 & Frágil \\
Monumental & 0,0 & Trivial \\
Atemporal & 3,0 & Transitório \\
Divino & 0,6 & Terreno \\
Equilibrado & 2,3 & Desproporcional \\
Modesto & 2,4 & Luxuoso \\
Acolhedor & 1,7 & Desagradável \\
Limpo & 3,9 & Poluído
\end{tabular}

Fonte: Elaborado pelos autores (2018). 
Começando com o altar, percebe-se no Quadro 1 que os pontos que os entrevistados mais concordaram indicam uma percepção sobre uma aparência 'limpa', 'bonita', 'sólida', 'durável' e 'acolhedora'. Nenhum dos resultados tendeu para a direita (lado negativo), o único ponto que chega mais perto do centro da tabela relaciona-se à aparência julgada como 'luxuosa' em detrimento de uma mais 'modesta', o que pode ter sido causado pelo seu tamanho vultoso, assim também, como indica o par 'Monumental-Trivial' no qual a opinião está mais deslocada para uma aparência monumental. Estas percepções podem ainda ter se desencadeado devido às características do material, já que o granito polido e bem trabalhado pode resultar nestas percepções.

Quanto aos resultados para o ambão, sutis diferenças foram registradas. Os itens 'sólido' e 'limpo' obtiveram exatamente a mesma pontuação no altar e ambão, demonstrando que o ambão possui características harmônicas com o altar afirmando o potencial semântico do conjunto. $\mathrm{Na}$ avaliação da sédia a maioria dos pontos passou a pender mais para o centro da tabela. Dois itens avaliados na leitura dos usuários indicam ausência de percepção quanto às características 'monumental' e 'divino'. São valores relevantes para o trabalho, já que o objetivo do projeto era despertar um aspecto divino à sédia, já que esse espaço como cita Paro (2014), não poderia reproduzir aquilo que se encontra nas ruas, no dia-a-dia, o comum. Esta leitura dos usuários pode ter sido influenciada pelo tamanho final da sédia e cadeira dos ministros, relativamente compactas se comparada as de outras igrejas. Essa mesma percepção pode também ter influenciado outros aspectos da sédia, sua aparência não muito 'acolhedora' e 'nobre'.

\section{Considerações Finais}

Este artigo propõe a observação de uma relação mais estreita entre o projeto de design e a aplicação de simbologia nos mobiliários litúrgicos. Neste sentido, alerta para um maior envolvimento de profissionais do design e arquitetura no processo de ideação, conceituação dos templos católicos e dos mobiliários litúrgicos.

Como já foi dito, design é linguagem. Por isso, é possível afirmar que é de extrema importância que produtos com funções simbólicas tenham seus aspectos sociais e espirituais projetados com a intenção de causar alguma sensação em seus usuários. Não é possível controlar essas sensações, ou seja, cada usuário ou observador poderá receber ou interpretar a mensagem de maneira diferente. Porém, no caso dos mobiliários litúrgicos, estes possuem critérios que já são preconizados pela Igreja. Mesmo assim, os mobiliários litúrgicos passam por um período em que o simbolismo acaba por não ser projetado, descaracterizando significados inerentes a essas peças. Isto pode refletir na atenção da assembleia e no sentido da oração e de ações litúrgicas.

A intenção é que o significado simbólico do mobiliário litúrgico não se perca com o tempo, e que o profissional de design/arquitetura esteja presente no planejamento do projeto e domine aspectos do simbolismo, resgatando a importância e expressão do altar, ambão e sédia como principais elementos do espaço sagrado católico. Além disso, que envolvam os usuários nos processo de design e avaliação, garantindo a qualidade simbólica tão importante para a fé cristã.

\section{Referências}

ALMEIDA, J. H.; BORTOLOTI, R.; FERREIRA, P. R. S.; SCHELINI, P. W.; ROSE, J. C. C. Análise das Propriedades Psicométricas de Instrumento de Diferencial Semântico. Psychology/Psicologia Reflexão e Crítica, v.27, n.2, p.272-281, 2014. 
ARAUTOS. Arautos do evangelho. In: São Vicente de Paulo. Disponível em: <http://www.arautos.org/especial/29981/Sao-Vicente-de-Paulo.html>. Acesso em: 19 jun 2016.

BAUDRILLARD, Jean. A Troca Simbólica e a Morte. São Paulo: Edições Loyola, 1996.

BONSIEPE, Gui. Design, cultura e sociedade. São Paulo: Edgard Blücher, 2011.

BOROBIO, Dionísio. A dimensão estética da liturgia: arte sagrada e espaços para celebração. São Paulo: Paulus, 2010.

DALBERTO, A. G. Presbitério da capela São Vicente de Paulo. 2015. 1 fotografia.

ELIADE, Mircea. O sagrado e o profano: a essência das religiões. São Paulo: Martins Fontes, 1992.

FERREIRA, Aurélio Buarque de Holanda. Novo dicionário Aurélio da língua portuguesa. Curitiba: Positivo, 2004. 2120 p.

LÖBACH, B. Design industrial: bases para a configuração dos produtos industriais. Tradução de Freddy Van Camp. 1. ed. São Paulo: Edgard Blücher, 2001.

LOPES, J. L.; NOGUEIRA-MARTINS, L. A.; ANDRADE, A. L.; BARROS, A. L. B. L. Escala de diferencial semântico para avaliação da percepção de pacientes hospitalizados frente ao banho. Acta Paulista de Enfermagem, v. 24, n. 6, p. 815-20, 2011.

MILANI, Eliva de Menezes. Arquitetura, luz e liturgia: um estudo da iluminação nas igrejas católicas. Rio de Janeiro, 2006.

Núcleo de Catequese Paulinas - NUCAP; PASTRO, Claudio. Iniciação à liturgia. São Paulo: Paulinas, 2012.

OSGOOD, C.E.; SUCCI, G. J.; TANNENBAUM, P. H. The measurement of meaning. Urbana [IL]: University of Illinois Press, 1957.

PARO, T. A. F. O espaço litúrgico como experiência mistagógica. Teocomunicação, Porto Alegre, v. 44, n. 3, p. 381-395, set/dez 2014.

PASQUALI, L. Instrumentação psicológica: fundamentos e práticas. Porto Alegre: Artmed, 2010.

PASTRO, Cláudio. Guia do espaço sagrado. São Paulo: Loyola, 1999.

RIBEIRO, Emílio Soares. Um estudo sobre o símbolo, com base na semiótica de Pierce. Estudos Semióticos, São Paulo, v.6, n.1: p.46-53, 2010.

ROQUE, Maria Isabel Rocha. Altar cristão: evolução até a reforma católica. Lisboa: Universidade Lusíada Editora, 2004.

SECRETARIADO NACIONAL DE LITURGIA. Instrução Geral ao Missal Romano. Secretariado Nacional de Liturgia (org.). Fátima: Gráfica de Coimbra, 2003.

SILVA, Frei José $O$. da. Os elementos fundamentais do espaço litúrgico para celebração da missa. São Paulo: Paulus, 2006.

SUDJIC, Deyan. A linguagem das coisas. Rio de Janeiro: Intrínseca, 2010.

Agradecimentos: à Coordenação de Aperfeiçoamento de Pessoal de Nível Superior - CAPES pelo apoio financeiro no processo de doutoramento. 